\title{
Differential effect of cigarette smoking on hydrogen peroxide and thiobarbituric acid reactive substances exhaled in patients with community acquired pneumonia
}

\author{
R.A. Stolarek1, M. Kasielski², J. Rysz³, P. Bialasiewicz¹, D. Nowak1
}

ABSTRACT: Differential effect of cigarette smoking on hydrogen peroxide and thiobarbituric acid reactive substances exhaled in patients with community acquired pneumonia. R.A. Stolarek, M. Kasielski, J. Rysz, P. Bialasiewicz, D. Nowak.

Background. This study was designed to investigate the effect of cigarette smoking on hydrogen peroxide $\left(\mathrm{H}_{2} \mathrm{O}_{2}\right)$ and thiobarbituric reactive substances (TBARs) concentrations in exhaled breath condensate (EBC) in patients with community acquired pneumonia (CAP).

Methods. $\mathrm{H}_{2} \mathrm{O}_{2}$ and TBARs concentrations in EBC were determined with spectrofluorimetrical assays.

Results. Non-smoking CAP patients $(n=24)$ exhaled 1.4, 1.8 and 1.7 times more $\mathrm{H}_{2} \mathrm{O}_{2}$ than the smoking patients with CAP $(n=19)$ as assessed one $(0.73 \pm 0.32 \mu \mathrm{M}$ v. $0.51 \pm 0.36 \mu \mathrm{M})$, three $(0.84 \pm 0.31 \mu M$ v. $0.47 \pm 0.24 \mu M)$ and five $(0.66 \pm 0.28$ $\mu \mathrm{M}$ v. $0.40 \pm 0.35 \mu \mathrm{M})$ days after admission $(\mathbf{p}<0.05$ in each case). Over 10 days of hospital treatment, mean level of exhaled $\mathrm{H}_{2} \mathrm{O}_{2} 0.45 \pm 0.22 \mu \mathrm{M}$ in CAP patients with smoking history was decreased if compared with $0.71 \pm 0.19 \mu \mathrm{M}$ exhaled $\mathrm{H}_{2} \mathrm{O}_{2}$ in CAP group ( $\mathrm{p}=\mathbf{0 . 0 0 5}$ ). On the contrary, TBARs concentration evaluated over entire study period was increased in smoking CAP patients (median $0.02 \mu \mathrm{M}$, range 0-0.32 $\mu \mathrm{M}$ ) compared with non-smoking group (median $0.01 \mu \mathrm{M}$, range 0-0.21 $\mu \mathrm{M}, \mathbf{p}<0.05)$. Concurrent, active smoking status was related with the decreased levels of $\mathrm{H}_{2} \mathrm{O}_{2}$ exhaled in breath condensate within the course of CAP but it appeared to increase levels of TBARs.

Conclusions. The differential alternations of oxidative parameters in EBC with respect to the smoking status might provide evidence of increased $\mathrm{H}_{2} \mathrm{O}_{2}$ decomposition and enhanced generation of reactive species in airways of CAP patients.

Monaldi Arch Chest Dis 2006; 65: 1, 19-25.

Keywords: Hydrogen peroxide, thiobarbituric acid reactive substances, cigarette smoking, reactive oxygen species, exhaled breath condensate, pneumonia.

\footnotetext{
1 Department of Experimental and Clinical Physiology and Biochemistry, Medical University of Lodz,

2 Center of Medical Education, Practical Training Center, Medical University of Lodz,

3 Department of Family Medicine, Medical University of Lodz, Poland.
}

Correspondence: Prof. Dariusz Nowak MD, Ph.D.; Department of Experimental and Clinical Physiology and Biochemistry; Medical University of Lodz; Mazowiecka St. 6/8; 92-215 Lodz, Poland; e-mail: dnowak@zdn.am.lodz.pl

\section{Introduction}

Reactive oxygen species (ROS) released by lung macrophages, monocytes and neutrophils are not only the pivotal line of defence against infection but also play a major role in chronic tissue damage. The reactivity and oxidising potential of ROS is related to its chemical form and concentration, local concentration of transition metal ions and the availability of reducing agents, as cellular glutathione. In this milieu, $\mathrm{H}_{2} \mathrm{O}_{2}$ and TBARs emerge as relatively stable and volatile products, which can be conveniently measured in exhaled breath condensate of the patients with either acute or chronic airway inflammatory state. Oxidative stress, explicitly, the imbalance between reactive oxygen species and antioxidant defence is a common finding in smoking subjects, patients with chronic bronchitis and chronic obstructive pulmonary disease (COPD) [1-4]. The enhanced generation of oxidants is being, however, counteracted by increased activity of some pulmonary intracellular antioxidant defence members such as catalase and glutathione along with numerous others $[5,6,7]$. Cigarette smoke is an abundant source of thiol reactive aldehydes that readily hinder the pool of reduced glutathione, the major intracellular antioxidant in respiratory tract lining [8]. More specifically, cigarette smoke extracts were shown to convert tyrosine into 3-nitrotyrosine, which implies that these oxidizing agents act as peroxynitrite, a radical of the highest oxidizing potential [9]. Moreover, the increased $\mathrm{H}_{2} \mathrm{O}_{2}$ itself in exhaled breath may be related to both enhanced ROS generation and depletion of antioxidant pool. Thus, the net result of the oxidant imbalance cannot be 
readily predicted based on the action of single redox pair. It cannot be excluded that cigarette smoking and COPD may in parallel exert such action in a disease involving a rapid influx of phagocytes as pneumonia. COPD and smoking status are likely to modulate $\mathrm{H}_{2} \mathrm{O}_{2}$ and TBARs levels in exhaled breath in response to bacterial infection in lower airways. The exhaled $\mathrm{H}_{2} \mathrm{O}_{2}$ was indeed found increased in breath condensate in patients with community acquired pneumonia, adult respiratory distress syndrome, COPD, asthma and after lobectomy [10-16]. However, the relation between exhaled $\mathrm{H}_{2} \mathrm{O}_{2}$ and clinical parameters or concomitant diseases was casual, limited or reported only incidentally $[10,17]$. To the best of our knowledge, none of the existing studies has elaborated on the effect of smoking status on the levels of exhaled $\mathrm{H}_{2} \mathrm{O}_{2}$ in acute pulmonary infection. In our experimental design, we studied effects of cigarette smoking status, as a confounding factor, on the time course of $\mathrm{H}_{2} \mathrm{O}_{2}$ and TBARs in exhaled breath in patients with community acquired pneumonia (CAP).

\section{Materials and Methods}

\section{Patients and treatment}

The study included 43 patients (12 women aged $65 \pm 13,31$ men aged $67 \pm 12$ ) with CAP admitted to Institute of Internal Medicine at Medical University of Lodz from May 1998 to September 2000 (table 1). Each enrolled patient had to meet the following inclusion criteria: (1) age at least 18 years; (2) a new infiltrate(s), consolidation or pleural effusion consistent with pneumonia on a chest radiograph at the day of admission; (3) at least two of the following signs and symptoms: new or increased cough, purulent sputum, auscultatory findings on pulmonary examination including rales and evidence of pulmonary consolidation, tachypnoea or hypoxemia, pleuritic chest pain; (4) at least one of the following signs and symptoms: fever (tympanic temperature of $>38.5^{\circ} \mathrm{C}$ ) or a history of fever for the current episode of CAP, total peripheral white blood cells (WBC) count of $>10000$ cells $/ \mathrm{mm}^{3}$ or $>15 \%$ immature neutrophils (bands) regardless of total WBC count or leucopenia with total WBC count $<4500$ cells $/ \mathrm{mm}^{3}$; (5) negative urine pregnancy teston the day of admission in cases of women with child-bearing potential. The exclusion criteria were: (1) female patient who is pregnant or breast-feeding; (2) aspiration pneumonia or hospital-acquired pneumonia; (3) cystic fibrosis, active tuberculosis, bronchiectasis, active malignancies, signs of disseminated infection, creatinine clearance of below $30 \mathrm{ml} / \mathrm{min}$, liver impairment (alanine aminotransferase ALT, aspartate aminotransferase AST or alkaline phosphatase levels greater than 3 times the upper limit of normal) or presence of any serious unstable, underlying disease; (4) immunodeficiency or concomitant medication that may suppress the antibacterial defense; (5) systemic inflammatory disease; (6) active alcohol or illicit drug abuse.

All but two patients in a group of CAP patients $(n=19)$ with mild COPD [18], were cigarette smokers: mean daily cigarette consumption was $19 \pm 7$ and the cumulative consumption was $31 \pm 14$ pack-years. Mild COPD and effectively controlled hypertension with angiotensin converting enzyme (ACE) inhibitors were the only accepted concomitant diseases in the study protocol.

The empiric antibacterial therapy was initiated on the first day after admission. The empiric antibacterial therapy was introduced at standard doses and continued for seven days. It included cephalosporins in 19 patients, quinolones in 9, cephalosporins combined with aminoglycoside in 9 cases, cephalosporins plus quinolone in 2 patients and amoxicillin with clavualate in 4 patients.

Drugs were administered daily at the standard dosages for 7 days. Concomitant medication included: N-acetylcysteine effervescent tablets 600 $\mathrm{mg}$ /day, theophylline $300 \mathrm{mg}$ twice a day and, ACE inhibitors (either captopril $12.5 \mathrm{mg}$ or $25 \mathrm{mg}$

Table 1. - Baseline characteristics of study subjects

\begin{tabular}{lccc}
\hline & $\begin{array}{c}\text { CAP patients } \\
\text { with smoking history }\end{array}$ & $\begin{array}{c}\text { CAP patients } \\
\text { without smoking history }\end{array}$ & Control group \\
\hline Number & 19 & 24 & 20 \\
Gender M/F & $16 / 3$ & $15 / 9$ & $14 / 6$ \\
Mean age, yrs & $66 \pm 11$ & $67 \pm 14$ & $50 \pm 10$ \\
BMI & $24.1 \pm 4.5$ & $23.1 \pm 3.7$ & $25.0 \pm 3.2$ \\
FVC\% & $63.8 \pm 17.4^{*}$ & $53.6 \pm 15.2^{*}$ & $103.6 \pm 19.3$ \\
FEV $\%$ & $55.9 \pm 20.3^{*}$ & $54.8 \pm 17.5^{*}$ & $100.6 \pm 20.4$ \\
FEV 1 FVC & $85.1 \pm 21.9$ & $98.6 \pm 15.0$ & $101.6 \pm 7.5$ \\
Pneumonic score & $3.2 \pm 1.3$ & $4.0 \pm 1.1$ & $0^{\#}$ \\
\hline
\end{tabular}

FVC and $\mathrm{FEV}_{1}$ are expressed as a percentage of the predicted value; \# -value assumed based on individual medical history and physical examination, no chest radiography was performed exclusively for this purpose; CAP- community acquired pneumonia, FVC-forced vital capacity, $\mathrm{FEV}_{1}$-forced expiratory volume in the first second, BMI-body mass index. $* \mathrm{p}<0.05$ versus control. 
two or three times a day or enalapril 10 to $20 \mathrm{mg}$ once a day). ACE inhibitors were used by 9 nonsmoking patients and in 2 smokers. All CAP patients, who were active smokers $(n=19)$ and the non-smoking patients $(\mathrm{n}=24)$, were treated with $\mathrm{N}$ acetylcysteine and theophylline starting from the admission day.

The group of control healthy subjects included 20 volunteers (14 men, 6 women) (table 1) who had neither ever smoked nor suffered from any infectious disease for at least 3 months. They were free from any medication and had no history of respiratory or atopic disease. Each patient involved in the study gave their informed consent and the study protocol was thoroughly reviewed and approved by the Ethics Committee at Medical University of Lodz.

\section{Study protocol}

At the day of admission the chest X-ray, serum chemistry, haematology, urinalysis were performed and blood and sputum specimens for culture were collected from CAP patients. The chest $\mathrm{X}$-ray was interpreted by both pulmonary consultant and radiologist and the intensity of pneumonic changes was ranked from 0 (no symptoms) to 11 points. The number of pulmonary fields (from 0 to 6 points) involved by inflammatory infiltrate (consolidation) was the first parameter to be considered. One or two points were added if the opacity was inhomogeneous and mostly hazy or dense and coalesce to form confluent areas of pulmonary shadowing, respectively. The score was increased by additional one or two points if pleural effusion with or without adhesions was present (bilateral effusion with adhesions were ranked with 3 additional points). Thus, the maximum total score of 11 refers to a patient with bilateral pleural effusion and dense confluent inflammatory shadows in all 6 pulmonary fields.

The results of sputum and blood culture identified etiologic agent as Streptococcus pneumoniae $(\mathrm{n}=14)$ and Haemophilus influenzae $(\mathrm{n}=7)$ in the majority of study subjects. In 22 patients, the etiology of infection disease remained undetermined. Additionally, the serum antibody tests excluded current infection with Chlamydia pneumoniae, Chlamydia trachomatis, Chlamydia psittaci, Mycoplasma pneumoniae and Legionella pneumophilia. Although 10 patients were discharged as soon as after 7 or 8 days and the analysis of the $10^{\text {th }}$ day exhaled breath condensate was not possible in their case, they were included in study results as long as they were undergoing the current therapy.

The pre-bronchodilator spirometry was performed with Flowscreen (Erich Jaeger GmbH Co., Germany) at days $1^{\text {st }}$ and $10^{\text {th }}$ just after EBC collection. The following parameters were also measured during the treatment: serum concentration of C-reactive protein (CRP) with Beckman Array 360 on the $1^{\text {st }}$ and $10^{\text {th }}$ day of treatment and WBC count with Technicon $\mathrm{H} 1$ on the $1^{\text {st }}$ and $10^{\text {th }}$ day, respectively.

\section{Collection of exhaled breath condensate}

The EBC specimens for $\mathrm{H}_{2} \mathrm{O}_{2}$ and TBARs assay were collected as previously described $[1,10]$. Briefly, EBC samples for $\mathrm{H}_{2} \mathrm{O}_{2}$ and TBARs assay were collected between 8 and 10 a.m., 24 hours (admission) and then 3, 5 and 10 days (discharge) after the antibiotics therapy had been started. Patients who were current active smokers were asked to refrain from cigarette smoking for $12 \mathrm{hrs}$ before EBC collection. If a patient failed to refrain from smoking, a sample collection was performed on the following day. This was the case with 5 patients; one on day $3^{\text {rd }}$, three on day $5^{\text {th }}$ and one on day $10^{\text {th }}$. EBC from healthy subjects was collected at the same time intervals. To avoid any effect of season on $\mathrm{H}_{2} \mathrm{O}_{2}$ exhalation [19], the healthy control were randomly paired with one patient with $\mathrm{CAP}$ and the EBC collections were performed at the same intervals. The patient respiratory rate during EBC collection ranged from 17 to 27 breaths per minute versus 16 to 19 per minute in healthy controls. Previous studies demonstrated that the concentration of $\mathrm{H}_{2} \mathrm{O}_{2}$ in $\mathrm{EBC}$ was unaffected by the range of five fold increase in respiratory rate and minute ventilation [1]. The samples of collected condensate were immediately processed in $\mathrm{H}_{2} \mathrm{O}_{2}$ and TBARs assays.

\section{Measurement of $\mathrm{H}_{2} \mathrm{O}_{2}$ and TBARs in exhaled breath condensate}

The concentration of $\mathrm{H}_{2} \mathrm{O}_{2}$ in $\mathrm{EBC}$ was measured with previously described method $[19,20]$. Briefly, equal volumes of EBC and HRP solution $(1 \mathrm{U} / \mathrm{ml})$ containing $100 \mu \mathrm{M}$ homovanillic acid were mixed and incubated for $60 \mathrm{~min}$ at $37^{\circ} \mathrm{C}$. Then, $0.1 \mathrm{M}$ glycine- $\mathrm{NaOH}$ buffer ( $\mathrm{pH} 12.0$ ) with $25 \mathrm{mM}$ EDTA was added and emission at $420 \mathrm{~nm}$ was determined spectrofluorimetrically using a Perkin Elmer Luminescence Spectrometer LS-50B (Norwalk, CT, USA) at excitation at $312 \mathrm{~nm}$. The regression equation was: $\mathrm{y}[\mu \mathrm{M}]=0.06764(\mathrm{x}-$ $\mathrm{x}_{\mathrm{o}}$ ) +0.152 (where $\mathrm{y}=$ micromoles of $\mathrm{H}_{2} \mathrm{O}_{2}$ per liter of exhaled breath condensate; $\mathrm{x}=$ intensity of emission at $420 \mathrm{~nm}$ expressed in arbitrary units; $x_{0}$ $=$ intensity of emission given by reference sample receiving distilled water instead of EBC) [19]. The content of TBARs in EBC was determined as previously described $[1,21]$. Concisely, $100 \mu \mathrm{l}$ of the condensate was mixed with $2 \mathrm{ml}$ thiobarbituric acid solution, boiled for $30 \mathrm{~min}$, allowed to cool down and chromogen was extracted with butanol. After centrifugation, TBARs were measured spectrofluorimetrically, excitation and emission at 515 $\mathrm{nm}$ and $546 \mathrm{~nm}$, respectively [21]. The respective regression equation was $\mathrm{y}[\mu \mathrm{M}]=0.120 \mathrm{x}-0.076$ (where $y=$ TBARs in $\mu \mathrm{M}, \mathrm{x}=$ intensity of emission at $546 \mathrm{~nm}$ expressed in arbitrary units). The lower level of $\mathrm{H}_{2} \mathrm{O}_{2}$ detection was $0.083 \mu \mathrm{M}$ [3]. Tetramethoxypropane was used as an external standard and TBARs assay sensitivity was $0.05 \mu \mathrm{M}$ [3]. For standard hydrogen peroxide solutions ranging from 0.1 to $0.5 \mu \mathrm{M}$ and tetramethoxypropane 0.1 $\mu \mathrm{M}$ and $0.5 \mu \mathrm{M}$ solution, $\mathrm{H}_{2} \mathrm{O}_{2}$ and TBARs in- 
traassay variability did not exceed $2 \%$ and $3 \%$, respectively.

\section{Statistical analysis}

Data is expressed as an arithmetic mean \pm standard deviation or median and range with respect to the data distribution. In the case of the data below method sensitivity, $\mathrm{H}_{2} \mathrm{O}_{2}$ (14 of 242 samples) and TBARs concentration (186 of 242 samples) in EBC was assumed to be a half of detection limit of 42 and $25 \mathrm{nM}$, respectively. The cumulative mean refers to the average from four time points including the admission, third, fifth and tenth day during the study, whereas mean is specifically the average from a single time point. The time course of variables was analysed with Student $t$ and Wilcoxon matched pairs tests based on sample distribution. The differences between groups were analyzed with Mann-Whitney $U$ test or Friedman ANOVA test. In all cases a $p$ value of $<0.05$ was considered significant.

\section{Results}

\section{The clinical outcomes}

The empiric antibiotics therapy was successful and all study patients finished the study. There was significant improvement in forced vital capacity (FVC) and forced expiratory volume in the first second $\left(\mathrm{FEV}_{1}\right)$ in pneumonia patients with a history of cigarette smoking $(\mathrm{n}=19)$ : FVC\% (percentage of predicted value) increased from $63.8 \pm 17.4$ to $80.6 \pm 20.7(\mathrm{p}<0.05) ; \mathrm{FEV}_{1} \%$ increased from $55.9 \pm 20.3$ to $67.8 \pm 28.7(\mathrm{p}<0.05)$ and $\mathrm{FEV}_{1} / \mathrm{FVC}$ increased from $85.1 \pm 21.9$ to $87.7 \pm 17.6(\mathrm{p}<0.05)$. Serum CRP level decreased from $5.4 \pm 1.9 \mathrm{mg} / \mathrm{dl}$ in CAP patients with smoking history and $11.3 \pm 11.7$ $\mathrm{mg} / \mathrm{dl}$ in patients with CAP alone (day 0) to $1.9 \pm 1.7 \mathrm{mg} / \mathrm{dl}$ and $3.0 \pm 2.9 \mathrm{mg} / \mathrm{dl}$ (day 10 ), respectively $(\mathrm{p}<0.05)$. In the same subgroups, WBC decreased from (day 0): $9.3 \pm 4.1 \times 10^{3} / \mu \mathrm{l} \mathrm{mg} / \mathrm{dl}(\mathrm{CAP}$ with smoking history) and $10.9 \pm 6.7 \times 10^{3} / \mu 1$ (CAP alone) to $7.4 \pm 2.9 \times 103 / \mu 1$ and $9.2 \pm 0.6 \times 10^{3} / \mu 1$ (day $10)$, respectively, but these changes were not significant.

\section{Effect of cigarette smoking on time course of $\mathrm{H}_{2} \mathrm{O}_{2}$ exhalation in subjects with $\mathrm{CAP}$}

The time course of $\mathrm{H}_{2} \mathrm{O}_{2}$ exhalation in smoking CAP patients in comparison with those with $\mathrm{CAP}$ alone is presented in figure 1. The mean $\mathrm{H}_{2} \mathrm{O}_{2}$ concentration in healthy subjects was $0.18 \pm 0.12 \mu \mathrm{M}$, and no relevant changes were found over the ten-day period observation in this group. The exhaled $\mathrm{H}_{2} \mathrm{O}_{2}$ level was found significantly increased in CAP patients with either cigarette smoking history or without any concomitant airway disease if compared with healthy subjects at every given time point in the study $(\mathrm{p}<0.05)$. There was a remarkable increase of $\mathrm{H}_{2} \mathrm{O}_{2}$ exhaled breath condensate levels in non-smoking CAP pa- tients if compared with smoking counterparts. These differences were significant on the first, third and fifth day of treatment (fig. 1), when nonsmoking CAP subjects exhaled 1.4, 1.8 and 1.7, respectively, times more $\mathrm{H}_{2} \mathrm{O}_{2}$ than those with CAP and smoking history. There was no increase of exhaled $\mathrm{H}_{2} \mathrm{O}_{2}$ within the first days after admission and treatment in smoking pneumonia patients. In non-smoking subjects with CAP, $\mathrm{H}_{2} \mathrm{O}_{2}$ level significantly changed with highest increase on the $3^{\text {rd }}$ day of antibiotics treatment and subsequently decreased. Ten days later, both groups reached the similar values of exhaled $\mathrm{H}_{2} \mathrm{O}_{2}$ ranging from $0.54 \pm 0.25 \mu \mathrm{M}$ in patients with CAP alone to $0.52 \pm 0.34 \mu \mathrm{M}$ in $\mathrm{CAP}$ subjects with cigarette smoking history. The mean $\mathrm{H}_{2} \mathrm{O}_{2}$ level did not varied between different time points in smoking CAP patients over the study period. However, the cumulative mean exhaled $\mathrm{H}_{2} \mathrm{O}_{2}$ in smoking CAP patients (during entire study period) was significantly decreased down to $0.45 \pm 0.22 \mu \mathrm{M}$ (median 0.50 $\mu \mathrm{M}$, minimum $0.10 \mu \mathrm{M}$, maximum $0.95 \mu \mathrm{M}$ ) if compared with $0.71 \pm 0.19 \mu \mathrm{M}$ (median $0.67 \mu \mathrm{M}$, minimum $0.40 \mu \mathrm{M}$, maximum $1.06 \mu \mathrm{M}) \mathrm{H}_{2} \mathrm{O}_{2}$ in non-smoking patients $(\mathrm{p}=0.005)$ The mean levels of $\mathrm{H}_{2} \mathrm{O}_{2}$ over the ten day study period in both patients groups still increased when compared to the control group with mean $\mathrm{H}_{2} \mathrm{O}_{2}$ levels of $0.18 \pm 0.12$ $\mu \mathrm{M}(\mathrm{p}=0.0001)$.

\section{Effect of cigarette smoking on the time course of TBARs exhalation in CAP patients}

The level of TBARs in exhaled breath condensate increased in smoking CAP patients on the first day of admission (fig. 2) compared to patients with $\mathrm{CAP}$ alone. Although three and five days after admission exhaled TBARs levels were still 3.3 and 2.3 times higher, they did not reach significance level due to high inter-individual variability. TBARs levels were not altered between different time points assessed in CAP patients without smoking history over ten-day treatment period. Also, in smoking patients with CAP the respective values did not change significantly over this time. The cumulative mean TBARs concentration (reffering to the average from four time points during the study) $0.08 \pm 0.11 \mu \mathrm{M}$ (median $0.02 \mu \mathrm{M}$, minimum $0.00 \mu \mathrm{M}$, maximum $0.32 \mu \mathrm{M}$ ) in smoking CAP patients during entire study period was similar to cumulative mean TBARs level of $0.03 \pm 0.05$ $\mu \mathrm{M}$ (median $0.01 \mu \mathrm{M}$, minimum $0.00 \mu \mathrm{M}$, maximum $0.21 \mu \mathrm{M})$ in patients with CAP alone $(p=0.27)$. However, this mean TBARs concentration evaluated over entire study period was significantly increased in smoking CAP patients up to $0.08 \pm 0.11 \mu \mathrm{M}$ (median $0.02 \mu \mathrm{M}$, minimum 0.00 $\mu \mathrm{M}$, maximum $0.32 \mu \mathrm{M}$ ) if compared with the control group $0.01 \pm 0.026 \mu \mathrm{M}(\mathrm{p}=0.0165)$. Further, 10 days after the initiation of antibiotics therapy, TBARs level decreased 4-fold in comparison to initial levels in smoking CAP patients but still, in statistical terms, the significance level was not reached presumably due to several early discharges in this group. 


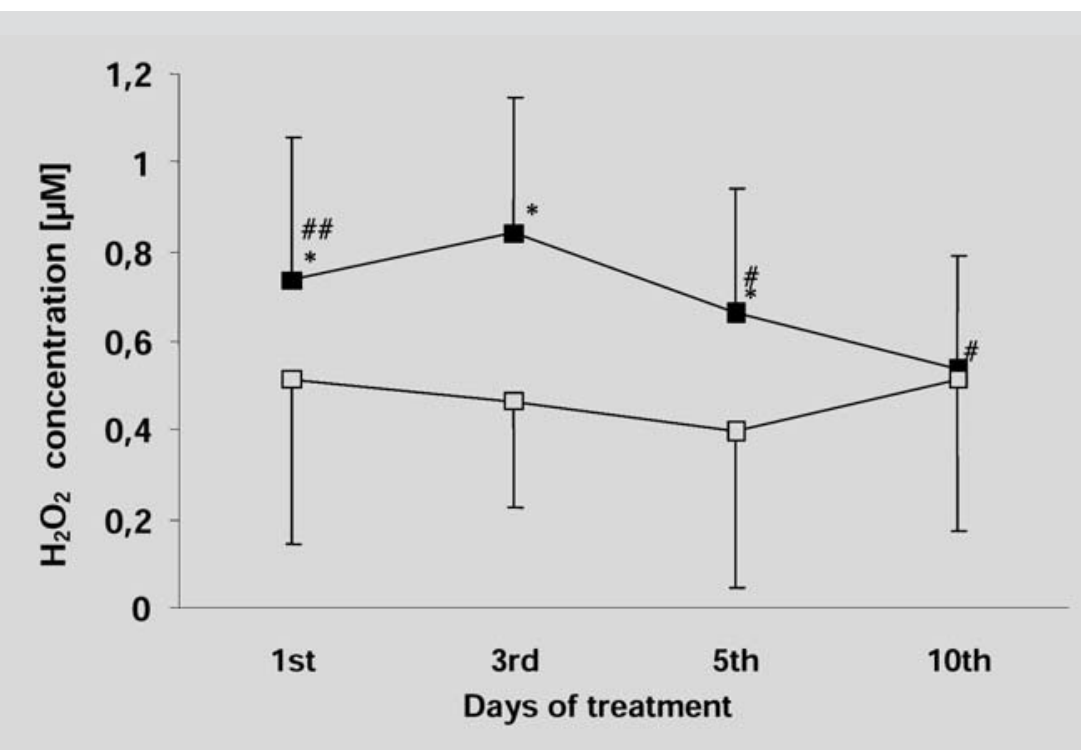

Fig. 1. - Effect of cigarette smoking on time-course of $\mathrm{H}_{2} \mathrm{O}_{2}$ exhalation by subjects with CAP - non smoking patients with CAP and without any concomitant respiratory tract disorder $(\mathrm{n}=24)$ - - smoking patients with CAP $(\mathrm{n}=19)$. Due to earlier patient discharge the mean values at $10^{\text {th }}$ day of treatment were obtained from 20 and 13 individual results for CAP patients without and with smoking history, respectively. * - significantly different vs. corresponding value found for non-smoking CAP patients - $\mathrm{p}<0.05$; \# - significantly different vs. $\mathrm{H}_{2} \mathrm{O}_{2}$ levels at 3 rd day; \#\# - different vs. $\mathrm{H}_{2} \mathrm{O}_{2}$ levels at $10^{\text {th }}$ day of treatment $-\mathrm{p}<0.05$.

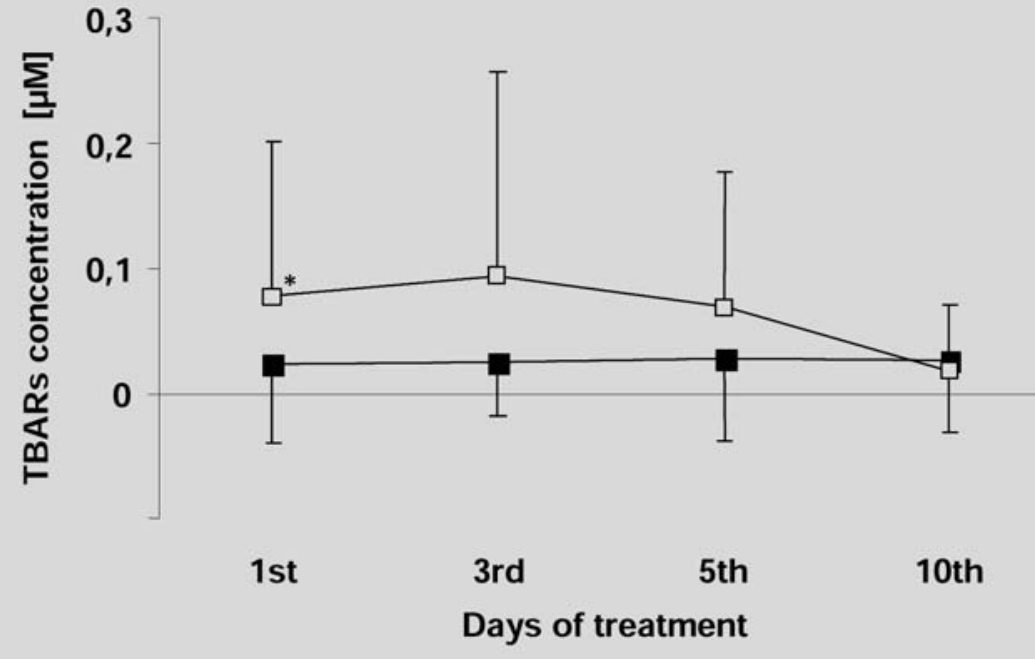

Fig. 2. - Effect of cigarette smoking on time-course of TBARs exhalation by subjects with CAP - non smoking CAP patients and without any concomitant respiratory tract disorder $(\mathrm{n}=24)$; $\square$ - CAP patients with smoking history $(\mathrm{n}=19)$. * - significantly different vs. corresponding value found for non-smoking CAP patients $-\mathrm{p}<0.05$. No significant changes in TBARs exhalation vs. value found at the day of admission (1 1 st day) were observed in both patient groups over the treatment period.

\section{Correlation between exhaled breath condensate and clinical parameters}

The cumulative mean (refering to the average from four time points during the study) level of expired $\mathrm{H}_{2} \mathrm{O}_{2}$ in CAP patients corrleated with serum CRP concentration on admission: $\mathrm{r}=0.42$ $(\mathrm{p}=0.046)$ and the $\mathrm{X}$ ray score: $\mathrm{r}=0.45(\mathrm{p}=0.032)$. Also, cumulative mean level of expired $\mathrm{H}_{2} \mathrm{O}_{2}$ in smoking CAP patients correlated with CRP on admission: $r=0.47$ ( $p=0.034)$, however, there was no correlation with the $\mathrm{X}$ ray scores.

\section{Discussion}

The most relevant finding from the current study is that hydrogen peroxide and TBARs level in exhaled breath condensate is altered by smoking status in patients with community-acquired pneumonia (CAP). In particular, concomitant cigarette smoking discriminated subjects with CAP in respect to the amount and time pattern of $\mathrm{H}_{2} \mathrm{O}_{2}$ exhalation for five days after the admission. Patients, who were non-smokers exhaled more $\mathrm{H}_{2} \mathrm{O}_{2}$ than the smoking counterparts, whereas TBARs, on the contrary to $\mathrm{H}_{2} \mathrm{O}_{2}$, was decreased in patients with CAP alone at the start of treatment.

Although, the overall time course of changes in exhaled $\mathrm{H}_{2} \mathrm{O}_{2}$ and TBARs in pneumonia patients does not appear as a surprising finding, the relevant changes of these parameters are not a common observation in exhaled breath condensate of patients with other pulmonary diseases. A recent study on a group of nineteen patients treated due to lower respiratory tract infections did not demonstrate any apparent changes in $\mathrm{H}_{2} \mathrm{O}_{2}$ concentration in exhaled breath condensate in the course of standard therapy of COPD exacerbations [22]. Also, in patients with mild asthma, $\mathrm{H}_{2} \mathrm{O}_{2}$ in exhaled breath condensate was reportedly at invariable level without any apparent changes over the course of therapy [23]. However, $\mathrm{H}_{2} \mathrm{O}_{2}$ was also found to decrease in exhaled breath in asthmatic patients treated with inhaled glucocorticosteroid for four weeks [24] and in COPD patients after long-term administration of $\mathrm{N}$-acetylcysteine [19]. The implications from these observations emphasize that the persistent state of bronchial inflammation could attenuate the acute phagocyte response to the infection in the airways. The antioxidant defence in chronic bronchitis or COPD is likely to be more prone to accelerate $\mathrm{H}_{2} \mathrm{O}_{2}$ decomposition [4], specifically including glutathione, catalase and myeloperoxidase $[6,7]$. Acute as well as chronic exposure to cigarette smoke, a major causative factor of chronic bronchitis and COPD was shown to elevate exhaled $\mathrm{H}_{2} \mathrm{O}_{2}[1,2]$. Cigarette smoke as a source of iron [25] may promote hydroxyl radical generation, peroxidative damage to lung tissue and 
TBARs formation in the airways [1]. On the other hand, COPD secondarily can increase the activity of catalase and glutathione peroxidase, concentration of reduced glutathione and antioxidant capacity of epithelial lining fluid of distal airways [7]. Numerous clinical and research evidence provide the data on the increase or attenuation of $\mathrm{H}_{2} \mathrm{O}_{2}$ released by lung phagocytes in response to chronic exposure to cigarette smoke. COPD was shown to enhance $\mathrm{H}_{2} \mathrm{O}_{2}$ exhalation [3]. Also, alveolar epithelial type II cells showed inhibited IL-8 mRNA expression and chemokine release that would further support the attenuation of neutrophil function in chronic bronchitis [26]. Contrary to the working notion that chronic inflammation would attenuate phagocyte function, certain compounds from smoke condensate were shown to upregulate $\mathrm{CD} 11 \mathrm{~b} / 18$ and increase the number of formyl-methionyl-leucyl-phenylalanine receptors on neutrophil surface along with two-fold increase in superoxide generation [27]. Increased lung iron content and underlying inflammatory response predispose to both oxidants- and enzymatic-dependent TBARs generation leading to higher exhalation of these compounds in pneumonia patients with COPD [28]. The attenuated exhalation of $\mathrm{H}_{2} \mathrm{O}_{2}$ in smoking patients with pneumonia in our study may hypothetically be linked to the increased release of catalase from macrophages in the aiways in smoking subjects [29].

Oxidative stress related with cigarette smoking may be too mild to elevate the concentrations of measured variables in exhaled breath condensate of CAP patients. This is consistent with the results of our previous study in which cigarette smoking did not affect elevated $\mathrm{H}_{2} \mathrm{O}_{2}$ and TBARs exhalation in subjects with stable chronic obstructive pulmonary disease [3]. Pre-existing chronic bronchitis enhances lung antioxidant defence, thus additional oxidant burden related with pneumonia did not result in a further rise in $\mathrm{H}_{2} \mathrm{O}_{2}$ exhalation. We did not observe this phenomenon in case of TBARs exhalation probably due to much more complicated TBARs metabolism, which involves free radical dependent and independent sources of generation and catalytic properties of iron [30]. We would assume that in our experimental setting the robust inflammatory response to bacterial infection and the oxidative burden in activated host defense phagocyte cells would contribute to increased involvement of $\mathrm{H}_{2} \mathrm{O}_{2}$ generation that was attenuated in smoking subjects with pneumonia. Further, the clinical relevance of alternations in breath condensate $\mathrm{H}_{2} \mathrm{O}_{2}$ levels in the assessment of the 'efficiency' of oxidative response to the infection should not be underestimated. We have previously demonstrated the positive correlation between pneumonic chest $\mathrm{X}$-ray score at the day of admission and the mean $\mathrm{H}_{2} \mathrm{O}_{2}$ level over the tenday hospitalisation period [10].

In summary, among our patients, the subjects with a history of cigarette smoking demonstrated decreased level of exhaled $\mathrm{H}_{2} \mathrm{O}_{2}$ and increased concentration of exhaled TBARs within up to five days after the diagnosis of CAP and initiation of antibiotics therapy. The decrease of $\mathrm{H}_{2} \mathrm{O}_{2}$ level in breath condensate may indicate for the enhanced decomposition of $\mathrm{H}_{2} \mathrm{O}_{2}$, impaired inflammatory response to bacterial infection or the attenuation of phagocyte oxidative response early in the course of infection, whereas increased TBARs seems to be associated with a delayed effect of increased oxidative stress. The time course of changes in exhaled $\mathrm{H}_{2} \mathrm{O}_{2}$ and TBARs appears to differentiate subjects with respect to smoking status. The relevance of these observations merits further research that could potentially improve not only our understating of chronic inflammation in smoking subjects, but also the clinical management of these patients.

Acknowledgements: This study was supported by Medical University of Lodz institutional grant no. 502-11-167.

\section{References}

1. Nowak D, Kalucka S, Bialasiewicz P, Krol M. Exhalation of $\mathrm{H}_{2} \mathrm{O}_{2}$ and thiobarbituric acid reactive substances (TBARs) by healthy subjects. Free Radical Biol Med 2001; 30: 178-186.

2. Nowak D, Antczak A, Krol M, et al. Increased content of hydrogen peroxide in expired breath of cigarette smokers. Eur Respir J 1996; 9: 652-657.

3. Nowak D, Kasielski M, Antczak A, Pietras T, Bialasiewicz P. Increased content of thiobarbituric reactive substances and hydrogen peroxide in the expired breath condensate of patients with stable chronic obstructive pulmonary disease. No significant effect of cigarette smoking. Respir Med 1999; 93: 389-396.

4. Repine JE, Bast A, Lankhorst I. Oxidative stress in chronic obstructive pulmonary disease. Am J Respir Crit Care Med 1997; 156: 341-357.

5. Cantin AM, Fells GA, Hubbard RC, et al. Antioxidant macromolecules in the epithelial lining fluid ao the normal lower respiratory tract. J Clin Invest 1990; 86: 962-71.

6. Linden M, Rassmussen JB, Pitulainen E, et al. Airway inflammation in smokers with nonobstructive and obstructive chronic bronchitis. Am Rev Respir Dis 1993; 148: 1226-1232.

7. Greening AP, Downing I, Wood NE, Flenley DC. Pulmonary antioxidants: catalase activity but not ceruloplasmin is increased in smokers (abstr). Am Rev Respir Dis 1985; 131: A385.

8. Reddy S, Finkelstein EI, Wong PS, Phung A, Cross CE, van der Vliet A. Identification of glutathione modifications by cigarette smoke. Free Radic Biol Med 2002; 11: 1490-1498.

9. Yamaguchi Y, Kagota S, Haginaka J, Kunitomo M. Peroxynitrite-generating species: good candidate oxidants in aqueous extracts of cigarette smoke. Jpn $J$ Pharmacol 2000; 82: 78-81.

10. Majewska E, Kasielski M, Luczynski R, Bartosz G, Bialasiewicz P, Nowak D. Elevated exhalation of hydrogen peroxide and thiobarbituric acid reactive substances in patients with community acquired pneumonia. Respir Med 2004; 98: 669-676.

11. Dekhuijzen PNR, Aben KKH, Dekker I, et al. Increased exhalation of hydrogen peroxide in patients with stable and unstable COPD. Am J Respir Crit Care Med 1996; 154: 813-816.

12. Dohlman AW, Black HR, Royall J. Expired breath hydrogen peroxide is a marker of acute airway inflammation in pediatric patients with asthma. Am Rev Respir Dis 1993; 955-960. 
13. Baldwin SR, Simon RH, Grum CM, Ketai LH, Boxer L, Devall LJ. Oxidant activity in expired breath of patients with ARDS. Lancet 1986; 1: 11-14.

14. Kietzmann D, Kahl R, Muller M, Burchardi H, Kettler D. Hydrogen peroxide in expired breath condensate of patients with acute respiratory failure and ARDS. Intensive Care Med 1993; 19: 78-81.

15. Sznajder JI, Fraiman A, Hall JB, et al. Increased $\mathrm{H}_{2} \mathrm{O}_{2}$ in the expired breath of patient with acute hypoxemic respiratory failure. Chest 1996; 3: 606-612.

16. Moloney ED, Mumby SE, Gajdocsi R, et al. Exhaled breath condensate detects markers of pulmonary inflammation after cardiothoracic surgery. Am J Respir Crit Care Med 2004; 169: 64-69.

17. Loukides S, Bouros D, Papatheodorou G, Panagou P, Siafakas NM. The relationships among hydrogen peroxide in expired breath condensate, airway inflammation and asthma severity. Chest 2002; 121: 338-346.

18. Duffell MG. Medicine for the practicing phycisian. In: Hurst JW. Boston, MA. PA: Butterworth Publishers, 1989: 880-908.

19. Kasielski M, Nowak D. Long-term administration of Nacetylcysteine decreases hydrogen peroxide exhalation in subjects with chronic obstructive pulmonary disease. Respir Med 2001; 95: 448-56.

20. Ruch W, Cooper PH, Baggiolinii M. Assay of $\mathrm{H}_{2} \mathrm{O}_{2}$ production by macrophages and neutrophils with homovanillic acid and horseradish peroxidase. J Immunol Meth 1983; 63: 347-57.

21. Yagi K. A simple fluorimetric assay for lipid peroxides in blood plasma. Biochem Med 1986; 15: 212-216.

22. van Beurden WJ, Smeenk FW, Harff GA, Dekhuijzen PN. Markers of inflammation and oxidative stress dur- ing lower respiratory tract infections in COPD patients. Monaldi Arch Chest Dis 2003; 59: 273-80.

23. Sandrini A, Ferreira IM, Gutierrez C, Jardim JR, Zamel $\mathrm{N}$, Chapman KR. Effect of montelukast on exhaled nitric oxide and nonvolatile markers of inflammation in mild asthma. Chest 2003; 124: 1334-1940.

24. Antczak A, Kurmanowska Z, Kasielski M, Nowak D. Inhaled glucocorticosteroids decrease hydrogen peroxide level in expired air condensate in asthmatic patients. Respir Med 2000; 5: 416-421.

25. Kamp DW, Srinivasan M, Weitzman SA. Cigarette smoke and asbestos activate poly-ADP-ribose polymerase in alveolar epithelial cells. J Investig Med 2001; 49: 68-76.

26. Witherden IR, Vanden Bon EJ, Goldstraw P, Ratcliffe C, Pastorino U, Tetley TD. Primary human alveolar type II epithelial cell chemokine release: effects of cigarette smoke and neutrophil elastase. Am J Respir Cell Mol Biol 2004; 30: 500-9.

27. Koethe SM, Kuhnmuench JR, Becker CG. Neutrophil priming by cigarette smoke condensate and a tobacco anti-idiotypic antibody. Am J Pathol 2000; 157: 1735-43.

28. Nowak D, Zieba M, Zawiasa D, et al. Changes of serum concentration of lipid peroxidation products in patients with pneumonia. Monaldi Arch Chest Dis 1996; 51: 188-93.

29. Hubbard RC, Ogushi F, Fells GA, et al. Oxidants spontaneously released by alveolar macrophages of cigarette smokers can inactivate the active site of alpha 1-antitrypsin, rendering it ineffective as an inhibitor of neutrophil elastase. J Clin Invest 1987; 5: 1289-95.

30. Janero DR. Malondialdehyde and thiobarbituric acidreactivity as diagnostic indices of lipid peroxidation and peroxidative tissue injury. Free Radical Biol Med 1990; 9: 515-540.

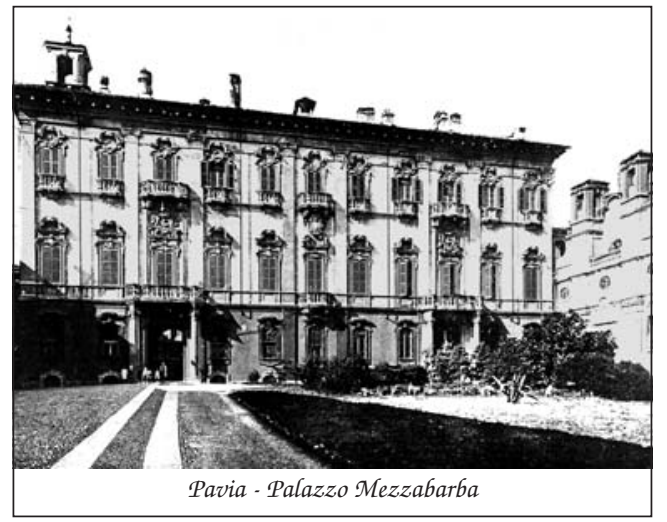

